\title{
Relation between hysterectomy and the irritable bowel: a prospective study
}

\author{
A Prior, K M Stanley, A R B Smith, N W Read
}

Department of Physiology and Nutrition,

Royal Hallamshire Hospital, Sheffield

A Prior

N W Read

Department of Obstetrics and Gynaecology, Jessop

Sheffield

K M Stanley

A R B Smith

Correspondence to:

Dr A Prior,

Department of Medicine,

University Hospital of

Manchester M20 8LR.

Accepted for publication 30 August 1991 Gastrointestina

Hospital for Women,

South Manchester,

\begin{abstract}
Some women with irritable bowel syndrome date the onset of symptoms to previous hysterectomy. To assess prospectively the incidence of gastrointestinal symptomatology arising de novo after hysterectomy, and to study the effect of surgery on pre-existing symptoms, 205 women completed a symptom questionnaire before and six weeks and six months after surgery. Beforehand, symptoms suggestive of irritable bowel syndrome occurred in $22 \%$ of patients. At six months after operation, $60 \%$ of these had improved or were symptom free while $20 \%$ had increased symptomatology. New gastrointestinal symptoms were present more than once per week in $10 \%$ of previously asymptomatic women. Constipation predominant irritable bowel syndrome was the commonest symptom complex seen de novo, occurring more than once per week in $5 \%$ of the group. No relation was found between new symptomatology and the type of hysterectomy, oophorectomy, or the administration of perioperative antibiotics. This study suggests that many women with pre-existing gastrointestinal symptomatology improve after hysterectomy. However, symptoms suggestive of irritable bowel syndrome do arise de novo in $10 \%$. As hysterectomy is common, gastroenterologists can expect to see women presenting with post-hysterectomy problems.
\end{abstract}

Gynaecological and gastroenterological practice often overlap. Women attending gynaecological

TABLE I Overall gastrointestinal symptomatology before and after hysterectomy

\begin{tabular}{|c|c|c|c|}
\hline Symptom & $\begin{array}{l}\text { Before } \\
(n=205) \\
\%(95 \% C I)\end{array}$ & $\begin{array}{l}6 \text { Weeks } \\
(n=201) \\
\%(95 \% C I)\end{array}$ & $\begin{array}{l}6 \text { Months } \\
(n=191) \\
\%(95 \% C I)\end{array}$ \\
\hline $\begin{array}{c}\text { Total IBS sym } \\
>1 / \text { month } \\
>1 / \text { week }\end{array}$ & $\begin{array}{l}22(16-28) \\
11(7-16)\end{array}$ & $\begin{array}{l}22(16-28) \\
16(11-22)\end{array}$ & $\begin{array}{l}19(14-25) \\
10(6-15)\end{array}$ \\
\hline $\begin{array}{l}\text { IBS constipati } \\
>1 / \text { month } \\
>1 / \text { week }\end{array}$ & $\begin{aligned} 10 & (6-15) \\
4 & (2-8)\end{aligned}$ & $\begin{array}{l}12(8-19) \\
11(7-16)\end{array}$ & $\begin{array}{ll}9 & (5-14) \\
5 & (2-8)\end{array}$ \\
\hline $\begin{array}{c}\text { IBS diarrhoea } \\
>1 / \text { month } \\
>1 / \text { week }\end{array}$ & $\begin{array}{ll}6 & (3-10) \\
5 & (2-9)\end{array}$ & $\begin{array}{ll}5 & (2-8) \\
2 & (\cdot 5-5)\end{array}$ & $\begin{array}{ll}4 & (2-8) \\
3 & (1-6)\end{array}$ \\
\hline $\begin{array}{c}\text { IBS alternatin } \\
>1 / \text { month } \\
>1 / \text { week }\end{array}$ & $\begin{array}{ll}6 & (3-10) \\
2 & (\cdot 5-5)\end{array}$ & $\begin{array}{ll}5 & (2-8) \\
3 & (1-6)\end{array}$ & $\begin{array}{ll}6 & (3-10) \\
2 & (\cdot 5-5)\end{array}$ \\
\hline $\begin{array}{c}\text { Non-IBS abdc } \\
>1 / \text { month } \\
>1 / \text { week }\end{array}$ & $\begin{array}{r}16(11-22) \\
8(5-13)\end{array}$ & $\begin{aligned} 10 & (6-15) \\
7 & (4-11)\end{aligned}$ & $\begin{aligned} 11 & (7-10) \\
5 & (2-9)\end{aligned}$ \\
\hline $\begin{array}{c}\text { Painless consti } \\
>1 / \text { month } \\
>1 / \text { week }\end{array}$ & $\begin{array}{ll}6 & (3-10) \\
3 & (1-6)\end{array}$ & $\begin{array}{lc}4 & (2-8) \\
3 & (1-6)\end{array}$ & $\begin{array}{lc}4 & (2-8) \\
3 & (1-6)\end{array}$ \\
\hline $\begin{array}{c}\text { Painless diarrh } \\
>1 / \text { month } \\
>1 / \text { week }\end{array}$ & $\begin{array}{ll}2 & (\cdot 5-5) \\
1 & (\cdot 01-3)\end{array}$ & $\begin{array}{ll}0.5 & (\cdot 01-3) \\
0.5 & (.01-3)\end{array}$ & $\begin{array}{l}1(\cdot 01-3) \\
0.5(\cdot 01-3)\end{array}$ \\
\hline
\end{tabular}

IBS = irritable bowel syndrome. clinics with pelvic pain have a high prevalence of symptoms suggestive of irritable bowel syndrom, ${ }^{12}$ and bowel habit and abdominal symptoms can vary with the menstrual cycle. ${ }^{3+}$ In addition, it is not uncommon for women attending gastroenterological clinics with irritable bowel syndrome to date the onset of their symptoms to previous gynaecological surgery, particularly hysterectomy. There is, however, no prospective data concerning the relation between hysterectomy and irritable bowl syndrome, and it is possible that some women who present with irritable bowel syndrome after surgery have had similar symptoms before their operation. ${ }^{56}$

This study aimed to assess prospectively the incidence of symptoms suggestive of irritable bowel syndrome arising de novo after hysterectomy and to study the effect of surgery on preexisting gastrointestinal symptomatology.

\section{Patients and methods}

The study group consisted of 205 consecutive patients admitted for hysterectomy to the Jessop Hospital for Women between October 1988 and June 1989. Women over the age of 75 years and those requiring postoperative chemotherapy or radiotherapy were excluded from the study. The mean age of the population was 48 years (range 27-75). Dysfunctional uterine bleeding, fibroids, and prolapse accounted for the indications for surgery in $80 \%$ of the patient group. Only $5 \%$ of patients underwent hysterectomy primarily for pelvic pain. Altogether, 105 women had a vaginal hysterectomy and 100 a simple abdominal hysterectomy. Thirteen of the group also underwent bilaterial oophorectomy and 58 had an anterior and/or posterior repair.

During their hospital admission and before hysterectomy, patients completed a questionnaire concerning the frequency and severity of abdominal pain, distension, bowel habit abnormalities, and urinary symptoms (frequency, urgency, and incontinence) in the 12 months before hysterectomy. A similar questionnaire was sent to patients six weeks and six months after surgery and returned by post. All questionnaires were completed by the patients and at no stage of the study were they directly interviewed. The questionnaire was based on that used in a previous study' and had been pretested on both patients and normal control subjects to ensure that the information collected was accurate Abdominal pain was rated by the patients as mild, moderate, or severe. Constipation was defined as less than three stools per week or straining at stool on more than $25 \%$ of occasions 
and diarrhoea defined as more than three loose stools per day. Case records were examined in order to establish parity, previous medical and surgical history, the clinical indication for hysterectomy, histological diagnosis, type of hysterectomy, use of perioperative antibiotics, and occurrence of perioperative complications.

\section{ANALYSIS OF DATA}

Data were analysed using a computer database and gastrointestinal symptomatology classified into the following subgroups:

(1) Constipation predominant irritable bowel syndrome (constipation plus non-menstrual abdominal pain and distension).

(2) Diarrhoea predominant irritable bowel syndrome (diarrhoea plus non-menstrual abdominal pain and distension).

(3) Alternating type irritable bowel syndrome (alternating diarrhoea and constipation plus nonmenstrual abdominal paid and distension).

(4) Non-irritable bowel syndrome pain (nonmenstrual abdominal pain with no disturbance in bowel habit).

(5) Painless constipation.

(6) Painless diarrhoea.

To be classified into the above groups, symptom frequency had to be greater than once per month.

Statistical analysis was performed using contingency table analysis with Yates's correction as appropriate. Significance was set at the $5 \%$ level. Results are expressed as group means with $95 \%$ confidence intervals $(\mathrm{CI})$.

\section{Results}

A total of 205 patients completed the preoperative questionnaire and the return rates at six weeks and six months were $98 \%$ and $93 \%$ respectively.

\section{PREOPERATIVE SYMPTOMATOLOGY}

Preoperative gastrointestinal symptoms are summarised in Table I. Symptoms suggestive of irritable bowel syndrome were found in $22 \%$ of women, with the constipation predominant subtype being noted most frequently. A disturbance of bowel habit without pain was seen in a further $8 \%$ of women. Approximately half of the women in all subgroups had symptoms more frequently than once per week.

POSTOPERATIVE SYMPTOMATOLOGY

Approximately $20 \%$ of women were experi-

TABLE II Outcome of gastrointestinal symptomatology at six months in patients with symptoms before hysterectomy

\begin{tabular}{llllll}
\hline & $\begin{array}{l}\text { Before } \\
(\text { no })\end{array}$ & $\begin{array}{l}\text { Resolved } \\
n o(\%)\end{array}$ & $\begin{array}{l}\text { Improved } \\
\text { no }(\%)\end{array}$ & $\begin{array}{l}\text { Same } \\
\text { no }(\%)\end{array}$ & $\begin{array}{l}\text { Worse } \\
\text { no }(\%)\end{array}$ \\
\hline Total IBS: & 45 & $15(33)$ & $12(27)$ & $9(20)$ & $9(20)$ \\
IBS constipation & 20 & $8(40)$ & $6(30)$ & $2(10)$ & $4(20)$ \\
IBS diarrhoea & 12 & $2(17)$ & $3(25)$ & $4(33)$ & $3(25)$ \\
IBS alternating & 13 & $5(38)$ & $3(23)$ & $3(23)$ & $2(15)$ \\
Non-IBS pain & 32 & $20(63)$ & $6(19)$ & $4(13)$ & $2(6)$ \\
Painless constipation & 12 & $4(33)$ & $2(17)$ & $3(25)$ & $3(25)$ \\
Painless diarrhoea & 3 & $1(33)$ & 0 & $1(33)$ & $1(33)$ \\
\hline
\end{tabular}

IBS = irritable bowel syndrome. encing symptoms suggestive of irritable bowel syndrome six weeks and six months after hysterectomy, and in half of these symptoms occurred more than once per week (Table I). Again, the constipation predominant subtype occurred most frequently (Table I). Comparison with preoperative symptomatology showed no significant changes in the proportion of patients in the various symptom groupings with the exception that the proportion of patients with abdominal pain and no bowel disturbance (nonirritable bowel syndrome pain) had fallen by one third at six months $(\mathrm{p}<0.01)$

\section{CHANGES IN INDIVIDUAL SYMPTOMATOLOGY}

Such an overall comparison does not take into account changes in the symptomatology of individual patients. Of the total patient group, $83(40 \%)$ had no gastrointestinal symptoms throughout the period of study. Table II summarises the outcome at six months for patients with abdominal symptoms preoperatively. Of the 45 women with symptoms suggestive of irritable bowel syndrome preoperatively, 33\% were symptom free at six months and $27 \%$ had improved, whereas $20 \%$ complained of increased symptoms. Preoperative non-irritable bowel syndrome abdominal pain had resolved completely in $63 \%$ of patients at six months.

\section{DE NOVO SYMPTOMATOLOGY}

After hysterectomy, approximately $10 \%$ of the 111 women who were asymptomatic beforehand experienced symptoms suggestive of irritable bowel syndrome more often than once per week (Table III). Constipation predominant irritable bowel syndrome was the commonest symptom complex to arise and occurred more than once per week in $9 \%$ of previously asymptomatic women at six weeks and $5 \%$ at six months. Painless constipation was noted for the first time by a further $2 \%$ of patients. Abdominal pain arising after surgery was always associated with a disturbance of bowel habit.

In view of the small numbers of patients with de novo diarrhoea and alternating bowel habit, analysis of possible associations with pre- and perioperative factors was restricted to patients with de novo constipation. The development of constipation did not seem to be associated with the type of hysterectomy, oophorectomy, the performance of a posterior repair, or the administration of perioperative antibiotics (Table IV).

\section{RELATION BETWEEN DE NOVO BOWEL AND} URINARY SYMPTOMS

No relation could be found between the development of de novo constipation and de novo urinary dysfunction after hysterectomy. Before surgery, 109 of the total of 205 patients had no bowel or urinary symptoms. Of these 109 women, only four developed both constipation and urinary symptoms (frequency (3), incontinence (1)) after surgery. However, there were six patients who experienced constipation without urinary problems and 25 with urinary problems 
TABLE III Gastrointestinal symptoms arising after hysterectomy more than once per week in the 111 patients asymptomatic before surgery

\begin{tabular}{lll}
\hline & $\begin{array}{l}6 \text { Weeks } \\
\%(95 \% C I)\end{array}$ & $\begin{array}{l}6 \text { Months } \\
\%(95 \% C I)\end{array}$ \\
\hline Total IBS: & $13(7-20)$ & $9(4-16)$ \\
IBS constipation & $9(4-16)$ & $5(2-11)$ \\
IBS diarrhoea & $2(0 \cdot 2-6)$ & $2(0 \cdot 2-6)$ \\
IBS alternating & $2(0 \cdot 2-6)$ & $2(0 \cdot 2-6)$ \\
Non-IBS abdominal pain & 0 & 0 \\
Painless constipation & $2(0 \cdot 2-6)$ & $2(0 \cdot 2-6)$ \\
Painless diarrhoea & 0 & 0 \\
\hline
\end{tabular}

IBS=irritable bowel syndrome.

(frequency and/or urgency (18), incontinence (7)) and no constipation.

\section{Discussion}

Our results show that preoperative symptom complexes suggestive of irritable bowel syndrome are common in women about to undergo hysterectomy but resolve or improve in $60 \%$ after the operation. The strong temporal association with surgery makes it very unlikely that this surprising result is just related to the natural fluctuation of the condition. A more likely explanation is that preoperative symptoms are related to the effect of the gynaecological condition or its treatment. The resolution of 'nonirritable bowel syndrome' abdominal pain after hysterectomy in many patients suggests that this symptom was of gynaecological origin. Improvement of bowel function may have resulted from withdrawal of treatment for the gynaecological condition. The commonest indication for hysterectomy was dysfunctional bleeding and fibroids, and these patients may have received iron supplements, mefenamic acid, or oestrogens and progestogens, all of which can cause bowel dysfunction. ${ }^{7}$ A further explanation is that the improvement in symptoms after surgery was a manifestation of the placebo effect which is appreciable in clinical trials in irritable bowel syndrome. ${ }^{8}$ However, although the patients might have expected their abdominal pain to resolve after surgery, it seems less likely they would believe that bowel habit problems would be resolved by hysterectomy.

De novo gastrointestinal symptomatology occurring more than once per week was seen in $10 \%$ of the study group. Why hysterectomy should trigger the symptoms of irritable bowel syndrome in some women is unknown. It has been postulated that perioperative use of antibiotics, particularly metronidazole, may predispose to its development by causing a change in bowel flora. ${ }^{9}$ Approximately $60 \%$ of patients who were asymptomatic before surgery received

TABLE IV Relation between perioperative factors and development of de novo constipation at six months

\begin{tabular}{lccc}
\hline & $\begin{array}{l}\text { Total } \\
\text { no }\end{array}$ & $\begin{array}{l}\text { De novo } \\
\text { constipation } \\
(1>\text { l/week })\end{array}$ & Ratio \\
\hline Total group & 111 & 10 & $11: 1$ \\
Vaginal hysterectomy & 51 & 5 & $10: 1$ \\
Abdominal hysterectomy & 60 & 5 & $12: 1$ \\
Bilateral oophorectomy & 9 & 2 & $9: 1$ \\
Posterior repair & 12 & 4 & $18: 1$ \\
Perioperative antibiotics & 73 & & \\
\hline
\end{tabular}

metronidazole perioperatively, but no association was observed between this and the development of bowel dysfunction, either six weeks or six months after surgery. A further possibility which merits consideration is that psychological factors may be of importance in development of new symptoms. Hysterectomy may be associated with the onset of anxiety and depression in some women $^{10}$ and it is known that psychological disturbance is common in patients with irritable bowel syndrome," 12 although community surveys suggest that psychopathology may influence whether patients present with symptoms rather than cause symptoms directly. ${ }^{13}$ it

Constipation was the commonest bowel disturbance after hysterectomy but the mechanism by which hysterectomy may cause this remains speculative. The observation that bladder and bowel dysfunction may occur in the same patients ${ }^{15}$ and the finding of abnormalities in rectosigmoid motility in women with constipation after hysterectomy ${ }^{16}$ have led to the suggestion that autonomic denervation of the pelvic viscera may occur during surgery. In the present study, however, there seemed to be no correlation between the development of de novo bladder and bowel symptoms. A recent study has also failed to show abnormalities of rectosigmoid motility or rectal sensitivity in women with constipation after hysterectomy. ${ }^{17}$ Finally, although it is now accepted that the pelvic nerves may be damaged during radical hysterectomy, this seems unlikely after vaginal or abdominal hysterectomy. ${ }^{18}$

Hysterectomy could also be implicated in the development of constipation through hormonal changes after oophorectomy as a decrease in plasma oestrodiol and its precursors has been reported in women with constipation. ${ }^{19}$ However, in keeping with accepted practice, most women undergoing bilateral oophorectomy in the present study were treated with hormone replacement therapy and were thus unlikely to be oestrogen deficient. It is also possible that decreased prostaglandin concentrations after hysterectomy could predispose to bowel dysfunction. Prostaglandins tend to increase bowel frequency and removal of the uterus, which is a potent source of prostaglandins, may therefore result in constipation. It has also been suggested that vaginal hysterectomy with posterior repair may specifically affect bowel function ${ }^{21}$ but this could not be confirmed in this study.

In conclusion, the results of the present study show that many women with pre-existing gastrointestinal symptoms improve after hysterectomy. De novo symptomatology occurs in $10 \%$ of those asymptomatic before surgery and is most often related to constipation. As hysterectomy is a commonly performed procedure, gastroenterologists can expect to see women presenting with bowel disturbance after hysterectomy.

1 Prior A, Wilson K, Whorwell PJ, Faragher EB. Irritable bowel syndrome in the gynaecological clinic. Dig Dis Sci bowel syndrome in
1989; 34: $1820-4$.

2 Hogston P. Irritable bowel syndrome as a cause of chronic pain in women attending a gynaecology clinic. $B M \mathcal{F} 1987 ; 294$ $93+5$

3 Davies GJ, Crowder M, Reid B, Dickinson JWT. Bowel function measurements of individuals with different eating patterns. Gut 1986; 27: 16+-9. 
4 Whitehead WE, Cheskin LR, Heller BR, Robinson JC, Crowell MD, Benjamin C, et al. Evidence for exacerbation of Crowell $\mathrm{MD}$, Benjamin $\mathrm{C}$, et al. Evidence for exacerbation of
irritable bowel syndrome during menses. Gastroenterology irritable bowel synd

5 Versi E. Effect of hysterectomy on bowel function. (Letter). $B M \mathcal{F}$ 1989; 299: 680.

6 Henshaw RC. Effect of hysterectomy on bowel function. (Letter). BMF 1989; 229: 680.

7 British National Formulary. British Medical Association and The Pharmaceutical Society of Great Britain. 1990

8 Klein KB. Controlled treatment trials in the irritable bowel syndrome: a critique. Gastroenterology 1988; 95: 232-41.

9 Alun Jones V, Hunter JO. Irritable bowel syndrome and Crohn's disease. In: Brostoff J, Challacombe T, eds. Food allergy and intolerance. London: Bailliere Tindall. 1987: allergy and $555-69$.

10 Oates M, Gath D. Psychological aspects of gynaecological surgery. Baillieres Clin Obstet Gynaecol 1989; 3: 729-49.

11 Young SJ, Alpers D, Norland CC, Woodruff RA. Psychiatric illness and irritable bowel syndrome: practical implications for the practising physician. Gastroenterology 1976; 70 $162-6$

12 Creed F, Guthrie E. Psychological factors in the irritable bowel syndrome, Gut 1987; 28: 1307-18.

13 Drossman DA, McKee DC, Sandler RS, Mitchell CM,
Cramer EM, Lowman BC, et al. Psvchosocial factors in the irritable bowel syndrome. A multivariate study of patients and nonpatients with irritable bowel syndrome. Gastroand nonpatients with irrita
enterology 1988; 95: 701-8.

14 Whitehead WE, Bosmajian L, Zonderman AB, Costa PT, Schuster MM. Symptoms of psychological distress associated with irritable bowel syndrome. Comparison of com munity and medical clinic samples. Gastroenterologv 1988 95: 709-14.

15 Taylor T, Smith AN. Effect of hysterectomy on bowe function. $B M 7$ 1989; 299: 300-1.

16 Varma JS, Smith AN. Abnormalities of colo-rectal function in intractable constipation following hysterectomy. Gut 1985 ; 26: A581-2.

17 Roe AM, Bartolo DCC, McC Mortensen NJ. Slow transit constipation. Comparison between patients with or without previous hysterectomy. Dig Dis Si 1988; 33: 1159-63.

18 Mundy AR. An anatomical explanation for bladder dysfunction following rectal and uterine dysfunction. $\mathrm{Br} \mathcal{F}$ Urol 1982; 54: 501-4.

19 Kamm MA, Lennard-Jones JE, Farthing MJG, McLean A Perry $\mathrm{L}$, Chard $\mathrm{T}$. Women with intractable constipation have an abnormality of adrenal steroid. Gut 1989; 30: A751. 20 Stanton SL. Effect of hysterectomy on bowel function. (Letter). BM7 1989; 299: 680 . 